\title{
The Dignity and Advancement of Bacon
}

By JESSE H. SHERA

F RANCIS BACON denied the circulation T of the blood, didn't understand the work of Galileo, rejected Gilbert on magnetism and Copernicus on the sun. He was not a scientist, but a lawyer, a practical politician, and a man of letters; he created no new science, but preached a new philosophy-though by William Harvey it was disparaged as the work of one "who writes philosophy like a Lord Chancellor." By which he meant, one may assume, that there was a certain amount of "ham" in Bacon. In every sense he was a child of his age; his contemporaneousness doubtless stems from the fact that today we are all Elizabethans at heart.

Yet Bacon was nothing if not a prophet, the bellwether of a new generation of scientists. He envisaged a world perfected by a reformed science, and though he made no striking or successful experiment contributing any important fact to man's store of natural knowledge, with conscious power and statesmanlike eloquence he gave authentic voice to a philosophy of inductive science unimagined by others who were, in reality, better scientists than he.

There was in Bacon's philosophy the spirit of adventure, even as in the exploits of Hakluyt, Drake, and Raleigh. Like Galileo, Tartaglia, Descartes, and Newton, he strove for the emancipation of physical doctrine from the presuppositions of scholastic ontology and espoused epistemology as the rational highway to the goal of all natural science. "It is idle," he wrote, "to expect any great advancement in science from the super-inducing and grafting of new things upon old. We begin anew from the very foun-

Dr. Shera is Dean, School of Library Science, Western Reserve University. He delivered this speech at Monteith College, Wayne State University, Detroit, Michigan, on the four hundredth anniversary of the birth of Francis Bacon.

dations, unless we would revolve forever in a circle, with mean and contemptible progress."

Bacon saw the realities of the universe as a self-contained whole and argued that the phenomena (or instances) comprising this totality must be assembled, examined, weighted against each other, and evaluated before the scientist dared indulge in generalization. He recognized that the doctrines of the Schoolmen were both outgrown and outworn, and in his view facts were the urgent need of his time; he defined a fact as "the unmasking of nature." So inane did he find the corpus of received philosophy that he saw no hope but in rejecting it entirely and substituting a new learning. Induction, he thought, would redress the empty rationalism of Scholastic science, which began with principles and deducted consequences; the new science would begin with facts derived from observation and experiment, progressing through successive steps to the formulation of a general principle. "From the gathering of countless grapes, ripe and in season," the wine of science would llow.

Nature itself, he maintained, does not lie. The source of all error is the impurity of the human mind, and the main function of eliminative induction is (for Bacon as for Aristotle) to assist in puri- 
fication of the intellect. Certain obstacles, which Bacon called "idols," render the mind inhospitable to innovation. Ready acceptance as truth of that which one wishes to be true; predisposition to individual prejudice and error; unfit choice of words, obscuring rather than clarifying the understanding; reliance on the authority of an obsolete systematic dogma inherited from medieval philosophy; the intellectual sterility and circularity of Scholastic "logic"; these were the "idols" that condemned the dignity and worth of human learning to languish in futility. The mind must be meticulously purged of all "anticipations," prejudices, and "idols" if it is to be prepared to comprehend the true essence of phenomena.

Synthesis of this "essence of phenomena" distills a totality of collected facts into the aforementioned wine of scientific truth. However, science cannot be distilled from uninterpreted sense experience, however assiduously the grapes of fact are gathered, sorted, and pressed. Bacon's progress toward truth via observation and experimentation left him stranded on the siding of positivism, for that which appears at first blush to be honest fact may later be shown to be nothing more than another "idol." Science does not advance solely by means of perceptual experience, nor is it served because man is making ever better use of his senses. Bold ideas, unjustified anticipations, and speculative thought must be hazarded if the scientist is to win his prize.

\section{Choice and Judgment}

Facts and phenomena are infinite in number, and the scientist must choose from those he discovers the few which may be relevant to his purpose. This exercise of choice is, of course, an act of judgment; and judgment formation is impossible without a theoretical frame of reference. The inductive verification of a theory implies a much more complicated process than empiricism in its usual form admits. Even the simplest determination of a physical fact implies a whole complex of theoretical statements and is significant only in relation to them. If science is to be realistic and orderly, empirical and rational methods must complement each other at every step; the theoretical can never be separated from the factual into a dichotomy. Bacon's experimentum crucis was impossible; he stumbled about in a world of isolated instances, unrelated particulars, and colorful but disorderly experiments, until the facts themselves exacted their own ironic penalty-he died as the result of exposure suffered when he left his carriage to stuff a chicken with snow in order to test the effect of low temperatures upon the rate of putrefaction.

Like any philosopher who distrusts abstraction, Bacon was driven by his inductive method to the use of classification as an instrument for ordering the world, a necessary prerequisite to the progress of human knowledge. Anticipating Locke's belief that ultimately all our ideas are the product of sensation, he adopted a psychological Gestalt for his classification and set forth, in the Latin (1623) edition of The Dignity and Advancement of Learning, the details of a scheme based on three human "faculties." "For sense, which is the door of the intellect," he wrote," is affected by individual objects only. The images of those individuals - that is, the impressions received by the senses-are fixed in the memory, and pass into it, in the first instance, entire as it were, just as they occur. These the human mind proceeds to review and ruminate on; and, thereupon, either simply rehearses them, or makes fanciful imitations of them, or analyzes and classifies them. Therefore, from these three fountains-Memory, Imagination, and Reason-flow these three emanations-History, Poesy, and Philosophy; and there can be no others." 
By ordering his classification upon man's cognitive power, Bacon gave fullest voice to his belief in the unity of all knowledge, which was organized for use into a configuration resembling the horns of Pan, broad at the base and pointed at the top, as all nature may be said to rise to a point. The individuals or instances comprising the base are infinite, but they may be collected into manifold species, which coalesced into genera which, by continued synthesis, progressed through more nearly universal generalities toward nature's natural end, unity. Its divisions, Bacon said, "are like branches of a tree that meet in one stem." The trunk represented one universal science, Bacon's Philosophia Prima, "which stem grows for some distance entire and continuous before it divides itself into arms and boughs." This great mother of all the sciences was "a receptacle for all such axioms as are not peculiar to any of the particular sciences, but belong to several of them in common." The body of these axioms he described as "displaying the unity of nature," and it was identification and demonstration of this unity that comprised the true office of Philosophia Prima.

Bacon's insistence upon the unity of science and learning has its obvious counterpart in the Hellenic belief in universal Sapience, and the Greeks linked the chain of the sciences into a Circle of Learning. But it imposed severe restrictions by drawing an absolute line of demarcation between the realm of the divine and the world of nature. Science was left with only the natural, hence its concern was limited to matter -the natural and physical sciences. But Bacon did not regard the speculative and the operational aspects of science as two kinds of knowledge, but rather as two professions or occupations operating with the same body of knowledge; one being concerned with an inquiry into causes, the other working toward the production of effects.

\section{Bacon's Debt to Aristotle}

Though Bacon's scheme for the partitioning of knowledge differed both fundamentally and in detail from those of his predecessors, its debt to Aristotle is apparent in several of its subordinate categories, and the Stoic Triad, as well as the Trivium and Quadrivium of the Scholastic curriculum are not quite concealed within it. Bacon separated civil from natural history, laying the foundation for a separation of science and philosophy-to him, civil history embraced all human affairs and natural history encompassed all the facts of nature. Perhaps he saw his classification as a framework within which he could set forth his observations and criticisms respecting each separate branch of knowledge and his proposals for remedying the deficiencies of the learning of his day. However, at the beginning of the seventeenth century the time was ripe for radical reform of the sciences-four centuries earlier another Bacon, Roger, had sought to define knowledge in terms of what men can do instead of what hypotheses they can formulate, but his impatience with Scholastic subtleties came a little too soon.

The errors in Francis Bacon's psychology, leading him to conclude that the mind operates in discrete water-tight compartments, that memory is confined to history, that history itself is no more than the recall of facts, that reason and imagination are opposing extremes, need not concern us here-after all, it was in the practical world of commerce, industry, agriculture, navigation, and court politics, rather than in the world of the mind, that Bacon felt most confident. However, like Samuel Johnson's preaching woman, Bacon's psychology is remarkable, not because it is faulty, but because it is psychology at all. 
The doctrine of the unity of knowledge, however imperfectly conceived in detail, had a special significance for the early seventeenth century. Bacon's classification not only helped to prepare the way for the enlightenment of the next century, but it also established a systematic plan of organization adopted by the authors and compilers of the dictionaries and encyclopedias which came to play such an important role in the dissemination of scholarship. "If we emerge from this vast operation," wrote Diderot in announcing his plans for a great French encyclopedia, "we shall owe it mainly to the Chancellor Bacon, who sketched the plan of an universal dictionary of sciences and arts at a time when there were not, so to speak, either arts or sciences. This extraordinary genius, when it was impossible to write a history of what men already knew, wrote one of that which they had to learn." Certainly it was the decision by Diderot and D'Alembert to make use of Bacon's system as the framework for their monumental synthesis of eighteenth century scholarship that firmly established Sir Francis as the supreme authority on classification.

\section{Universally Adopted}

To the close of the nineteenth century, and even almost to the present time, Bacon's tri-partite division of knowledge has remained unchallenged (except by Brunet) as the pattern to be followed by bibliographers and librarians in England, France, and especially in Italy. Rhodius, Clemens, Naudé, Bouillaud, and Garnier all employed the Baconian triad, with modifications. On this side of the Atlantic, Thomas Jefferson adopted the Baconian scheme for the organization of his own library, and when his books were sold to the United States government after the War of 1812 , his classification (based on Bacon's) was accepted as the organization plan for the Library of Congress and remained in use until shortly after 1900 , when the present system was devised by Martel and Hanson. Thaddeus Mason Harris, when librarian of Harvard College, used Bacon, as modified by Diderot and D'Alembert, for the ordering of his list of titles recommended for purchase by the small association libraries springing up along the Atlantic coast and in the Middle West during the late eighteenth and early nineteenth centuries. But, of course, it was Melvil Dewey's use of the "inverted Baconian" of William Torrey Harris for the general plan of the Dewey decimal system that established Bacon as the strongest single influence in bibliographic organization. And the adoption of the Dewey pattern by the International Institute of Bibliography for its universal decimal classification gave the Baconian influence an almost impregnable position throughout the world. For better or for worse, librarians and bibliographers will probably suffer with Bacon for a good many generations more.

The popularity of Bacon's schemes for bibliographic purposes is easily understood, for it is simple in concept, flexible, and readily applicable to practical situations. Philosophically, it rests on two assumptions: first, that books, being products of the mind, a scheme that derives from human faculties would seem to be particularly appropriate for their organization; and second, that books are themselves "facts," "instances," or entities, and therefore it must follow that the construction of a bibliographic classification is in itself a manifestation of the inductive process from which a taxonomic ordering will emerge. That such reasoning misconstrued the purpose of bibliographic organization, not to say the character of the book, is beside the point. Bacon, when he devised his system, had no notion that it would ever be used to order books in a library or entries in a bibliography. Librarians, on the other hand, have made use of whatever was readily available to them, and 
the Baconian triad seemed to meet their needs. Librarians have always been a practical breed, too often painfully so, not much given to thoughtful contemplation of the philosophical considerations that underlie their craft.

\section{Bacon's Contributions Appraised}

In the final analysis, then, how does one appraise the contribution of this fascinatingly complex man?

Bacon's perception of the intellectual bankruptcy of Scholasticism, and the imperfections of its method, led him to set forth ideas which dramatized the widening intellectual breach that separated his day from the Middle Ages. He invested science with a civic dimension which made it a comfortable democratic doctrine within which could develop a vocation for the betterment of man's estate that was not the monopoly of an aristocracy, either of birth or mentality, but could be shared by all. In the clarity and vigor with which he denounced the older philosophies, he stood above his less articulate contemporaries, though he preached much more successfully than he practiced.

Though he failed to recognize that the delicate process of observation is intimately interrelated to the philosophical atmosphere within which it is conducted, he did recognize, perhaps better than any other of his day, the extreme diffculties inherent in any attempt to ascertain accurately the facts of nature. To a striking degree he anticipated John Locke's belief that all human ideas are ultimately the product of sensation. This concept was not only implicit in the Novum Organum, but was the very foundation of his system of classification. Thus in the "practical" orientation of his philosophy, reinforced a half-century later by Locke's Essay Concerning Human Understanding, Bacon can properly be regarded as the progenitor of certain characteristically English schools of thought in psychology which have profoundly affected the course of scientific inquiry.

It was, however, in his attitude toward the importance of language and communication that his ideas seem most astonishingly modern. His "Idols of the Market-Place" anticipated today's general semantics: "men believe that their reason governs words ...., but it is also true that words react on the understanding." He presaged modern linguistics by pointing out the errors arising from the tendency to hypostatize language (that is, through words to attribute reality to that which does not exist), and the failure to recognize the open texture of language (that is, that words can be so confused and ill-defined that they can destroy rather than promote human communication). Thus, he arrived at the conclusion that a familiar word may have no definition which rightly fixes its meaning. As he said, the word is "a mark loosely and confusedly applied to denote a variety of actions which will not bear to be reduced to any consistent meaning," and thus to know its use fully, one must turn not only to definition, but also to the ways in which it is employed. Here, indeed, were germs of linguistic concepts that gave rise to such divergent twentieth century analyses as those of Whorf, Charles Morris, Korzybski, and others.

Also, in the sixth book of the English version of the De Augmentis, Bacon inquired into the capacity of "discourse," both written and oral, to convey the thought of one man to another. Here, especially in his treatment of ciphers and other non-vernacular forms of communication, he considered the transmission of information in ways that are strikingly suggestive of the problems of modern documentation, information theory, and symbolic logic, even hinting at Cybernetics.

Furthermore, in the first edition of the Advancement, in the Novum Organum, 
and in the New Atlantis, Bacon urged the association of scientists in cooperative exploration of natural phenomena, paying little heed to theory and none whatever to traditional philosophizing. That his vision inspired the founders of the Royal Society is evident from the testimony of Locke, Boyle, and the first officers of that organization who frankly regard themselves as his disciples. Admittedly, they were so fired by the Baconian enthusiasm for the inductive method that they were too filled with the wonders of nature, too preoccupied with the practical utility of what they were doing, and too impatient with the dull routines of systematic inquiry, to subject themselves to the rigorous selfdiscipline that is the hallmark of the true scientist. Yet in the spell cast over these brilliant young men who heralded the dawn of a new scientific age is to be found the germ of today's cooperative, or team, research. Bacon underestimated the task of exploring all the phenomena of nature, there can be no doubt about that; but he knew that it was a big job and that it could never be brought to successful completion by individual scholars working in isolation. There may have been more truth in Harvey's jibe than he realized, for what seventeenth century science seems to have needed most was a "Lord Chancellor." Perhaps this was Bacon's greatest contribution of all, that after four hundred years he can, to paraphrase his own words, still "ring the bell which calls the wits together."

\section{Photocopying by Libraries}

The following pertinent statement concerning photocopying by libraries is taken from the July 1961 Report of the Register of Copyrights on the General Revision of the U.S. Copyright Law, pp. 25-26:

\section{The Problem}

"The application of the principle of fair use to the making of a photocopy by a library for the use of a person engaged in research is an important question which merits special consideration. This question has not been decided by the courts, and it is uncertain how far a library may go in supplying a photocopy of copyrighted material in its collections. Many libraries and researchers feel that this uncertainty has hampered research and should be resolved to permit the making of photocopies for research purposes to the fullest extent compatible with the interests of copyright owners."

\section{Recommendations}

"The statute should permit a library whose collections are available to the public without charge to supply a single photocopy of copyrighted material in its collections to any applicant under the following conditions:

“(a) A single photocopy of one article in any issue of a periodical, or a reasonable part of any other publication, may be supplied when the applicant states in writing that he needs and will use such material solely for his own research.

“(b) A single photocopy of an entire publication may be supplied when the applicant also states in writing, and the library is not otherwise informed, that a copy is not available from the publisher.

"(c) Where the work bears a copyright notice, the library should be required to affix to the photocopy a warning that the material appears to be copyrighted." 